\title{
Dealing with resistant teachers while maintaining the vision: How novice social justice leaders "do" instructional leadership
}

Colette Cann, Ph.D.

Assistant Professor, Vassar College

Janette Hernandez,

Regional PK-8 Executive Officer of Oakland Unified School District

ABSTRACT: This research examines how novice social justice leaders provide instructional leadership to underperforming, resistant teachers in urban schools. Using a critical race theoretical framework, we analyze seventy-five oral stories told by novice leaders during a leadership support program. We find that these leaders, limited in their repertoire of strategies and motivated to quickly improve the classroom experiences of their youth, define instructional leadership as monitoring and "evaluating out" teachers who do not meet their expectations for instruction. Such instructional leadership results in what we term "hyper-bureaucratized" actions and a lack of emphasis on relationship building with teachers. This compromised conception of instruction leadership, though, allows them to continue to advocate for students even when their own lack of experience impedes their ability to support underperforming teachers to improve classroom instruction. Thus, novice social justice leaders are buoyed in their work and commitment to transformative leadership, even as they struggle to support underperforming teachers.

\section{Introduction}

This article looks at how novice social justice school leaders in urban schools come to think about, make sense of and play the instructional leadership role. Prior research primarily examines the challenges novice leaders face (for example, Brill, 2008; Karpinski, 2008; Loder and Spillane, 2005), the experiences of social justice leaders in schools (for example, Furman, 2012), or the importance of instructional leadership (for example, Bryk, Sebring, Allensworth, Luppescu \& Easton, 2010; Louis, Leithwood, Wahlstrom \& Anderson, 2010). Rarely has the literature considered their intersection to glean a more nuanced perspective of how novice social justice leaders go about the work of instructional leadership. The high turnover of school leaders in urban schools [see Cuban's (2010) discussion of the "burn and churn" teacher phenomenon extending now to teachers] ensures that each year a steady stream of leaders enters this work. Recently, the discourse around leadership has turned to social justice, particularly as leadership preparation programs have begun to focus their curricular and pedagogical attentions on socially just change in urban public schools (Rigby, 2012). In some instances, "social justice language" has been appropriated by both neoconservative and progressive agendas alike to describe polar opposite policy, actions and visions (Furman, 2012; Cambron-McCabe \& McCarthy, 2005). These shifts in foci and the reality of an ever-present novice cohort of leaders in urban schools justify a closer accounting of how these leaders view 
and enact a social justice instructional leadership role.

In this present research, we collected the experiences and stories of ten novice social justice leaders that recount their efforts and challenges in providing instructional leadership; in particular, we look at how they work with resistant and recalcitrant teachers. This research illuminates the limited toolbox from which they draw in this work as novice leaders and the resulting compromises they make to stay true to their visions of equity and social justice in public schools.

\section{Theoretical Framework}

We draw from the critical race theory (CRT) literature in legal studies and education to frame our research because CRT centers race and racism and, in doing so, provides a lens through which to understand and counter racial oppression. We briefly outline the central tenets of critical race theory (Dixson and Rousseau, 2006; Ladson-Billings and Tate, 1995). First, critical race theorists acknowledge that racism is ordinary and pervasive, not isolated to individual prejudiced acts. Racism operates systemically and is one of many oppressive foundations upon which schools are built. Further, White folks have historically benefited from this system of racism - even during seeming efforts to dismantle racial privilege. Termed "interest convergence" by Bell (1980), progressive legislation, policy and social action is likely to succeed, he argued, only when it actually supports the interests of those already in power. As well, critical race theorists argue that narrative is a powerful tool of the oppressed and that it is critical to claim their own unique voice and to use it to describe the experiences of people of color. Narratives of people of color contribute importantly to the field of education and to bringing about social change in schools. Fourth, critical race theorists encourage researchers to consider how race intersects with gender, sexuality and (dis)ability to create disparate experiences with oppression. And, finally, CRT is a scholarship of activism that goes beyond theorizing to direct action with and upon the world.

We use CRT as a lens through which to approach this study for several reasons. First, the school leaders that comprise the sample in this study sought out a leadership preparation program that focuses on creating more equitable and socially just schools. This program, the Principal Leadership Institute (PLI) at the University of California, Berkeley, worked closely with these developing leaders to think critically about the role of institutional racism in the construction of inequity in our public schools [what Ladson-Billings, in her 2006 address to the American Educational Research Association (AERA), referred to as the education debt owed to poor, immigrant and/or youth of color resulting from centuries of oppressive "historical, economic, sociopolitical and moral decisions and policies" (p. 5)]. The school leaders in this study embrace as a part of their identity as leaders that their work is about racial justice.

For example, the PLI uses a field-tested rubric that they designed over ten years time that identifies the critical elements of effective leaders in urban schools. Importantly, element three (of seven) highlights "equity and advocacy" as a key stance of effective leaders. The rubric states:

A primary leadership responsibility is to deeply understand and consistently reflect on his/her identity in a racially and culturally diverse setting.... Through purposeful training and development, s/he learns to facilitate formal and informal conversations about race and equity in the service of accomplishing substantial academic, civic and social-emotional goals. (p. 31, Tredway, Stephens, Leader-Picone, \& Hernandez, 2012)

As well, graduates from the PLI seek and accept positions in urban public schools, populated primarily by youth of color. Urban schools are, more often than not, racialized spaces, with the majority of teachers (and leaders) White, while the student population is comprised of students of color (Picower, 2009). The issues they confront in their work, issues such as racially segregated academic and social spaces (Oakes, 1985/2005 and Tatum, 1997), result from both everyday and institutional racism.

Further, while the majority of administrators in U.S. public schools are White, the majority of participants in this study are school leaders of color, due in large part to the purposeful recruitment efforts of the PLI. 
We privilege their stories in this study because it is their experiences and their words that might serve in "jarring [the] complacency" (Delgado, 1989, p. 2440) of those who subscribe to stock stories about effective leadership as technocratic, impersonal, value-free and apolitical. Ladson-Billings and Tate (1995) argued, "Stories by people of color can catalyze the necessary cognitive conflict to jar dysconscious racism" (p. 58). Their stories serve to support like-minded social justice leaders in this difficult work and serve as an outlet for their own frustrations and challenges (Lawrence, 1995); they also inform the leadership field about how leaders focused on racial and social justice do the work of bringing about social change in schools.

\section{Literature Review}

We draw from three bodies of literature (instructional leadership, novice leadership and social justice leadership) to inform our study. We look at each in turn.

\section{Instructional Leadership}

The term "instructional leadership" has been overused almost to the point of becoming irrelevant (Leithwood," Louis, Anderson \& Wahlstrom, 2004). Rigby (2012) argued that, even after over thirty years of research on instructional leadership, there is "no consensus on what it means" nor how to do it effectively (p. 1). She contended, in fact, that this notion of instructional leadership serves effectively as a reflection of changing foci in the educational realm; its meaning morphs in response to the latest cutting edge ideas in the field of education. Despite this (or rather because of the confusion surrounding this term), we take time here to review the literature that helped us think through its meaning.

Over the past three decades, research has attempted to define instructional leadership. Presently, many of these efforts to define it are actually seen in leadership rubrics used in various leadership preparation programs. Rigby (2012), for example, noted almost ten different rubrics in use from the late 1980s to the present that all contribute to present conceptions of instructional leadership. The Leadership Connection Rubric (Tredway et al., 2012) used in the PLI program, for example, was created as a tool to observe and supervise leaders in their work; yet, it also serves to synthesize decades of research and over ten years of practical work with leaders in the PLI. The rubric was collaboratively developed with district leaders and researchers and has been field-tested with twenty-five school leaders since 2000. In this rubric, they identified seven critical elements that are "essential building blocks of effective leadership. These elements codify fundamental components of the leadership chemistry and, in the right combination, yield a personal 'formula' for effective leadership" (Tredway et al., 2012, p. 3).

With regard to instructional leadership (element 4 of the rubric), Tredway et al. (2012) discussed three important aspects of instructional leadership. First, the instructional leader must attend to the creation and maintenance of a learning environment that is rigorous in the core areas of math and language literacy as well as art and science. Second, s/he must be fluent in and support fidelity to state standards while also insisting on the use of culturally relevant curricula and pedagogy to buttress the learning of students historically marginalized by standards that often privilege the cultural capital of the dominant racial group. Third, instructional leaders must recognize that teacher work with youth directly affects student learning outcomes; to increase the learning of youth, the work of instructional leaders must necessarily focus on increasing the capacity of teachers to do their work in the classroom. This often includes providing opportunities for teachers to learn and grow as pedagogues through professional development, coaching and supervision.

The research supports this conception of instructional leadership as building a rigorous learning environment that sets high expectations for learning and supporting teachers in their work to meet these expectations. Two recent empirical pieces confirm this. Bryk et al. (2010) articulated several dimensions to instructional leadership. Among these, they included the support and supervision of teachers' development, particularly in service of a challenging and substantive learning environment for students. Louis et al. (2010), in a comprehensive study of almost 200 schools, found similarly that instructional leadership that focused on articulating high expectations for student learning and supporting the growth and development of teachers to 
meet the diverse needs of their students to meet those expectations were critical.

While it is important to understand how instructional leadership is understood and defined in the research, it is at least equally as important to consider how school leaders, themselves, understand their own work as instructional leaders. Research shows that school leaders generally agree that instructional leadership is important in their work (Reeves, 2004) and novice leaders are no exception (Brill, 2008). Brill defined instructional leaders as those who "very simply, make the hard decisions and take the necessary actions to ensure that all students are learning" (p. 63, emphasis his). Such instructional leadership can come in the form of supervision, collaboration and/or evaluation. All forms provide some level of professional growth and development for teachers. New leaders believe the role of instructional leader to be their most significant way to affect student achievement

In a qualitative study of twenty school leaders, Reitzug, West and Angel (2008) examined how school leaders defined their work as instructional leaders. They found that school leaders defined their work in one of four ways. Twenty percent of their sample viewed instructional leadership not as direct pedagogical action taken with teachers, but as building relationships with teachers and students such that they felt supported and appreciated. Reitzug et al. wrote:

[I]n relational instructional leadership, increased learning and improvement in instruction does not occur as a result of working directly with the instructional program but rather as a byproduct of relationship building - specifically, the principal's efforts to help students and faculty feel better about themselves and thus try harder and take more pride in their work. ( $p$. 697)

Twenty-five percent of the interviewed school leaders viewed instructional leadership as the detailed work of providing leadership in the process of aligning curricula with state standards and using data to drive instruction. Referred to as "linear instructional leadership," such a "structural functionalist" perspective supports the following idea:

[S]ystems can be designed so that one action, process, structure, or intervention will lead to a subsequent desired outcome, which will then lead to the next desired outcome and so on down a causal chain. In addition the system can be carefully monitored and feedback loops can be implemented so that all aspects of the system remain in compliance with what has been designed and is desired. (p. 699)

Three leaders were identified as having an "organic instructional leadership" perspective. That is, they viewed their responsibility as providing the opportunities for teachers to work collectively to address issues that arise within the community; using professional learning communities, for example, they encouraged "inquiry and discourse" among their teachers, often raising more questions of their teachers than answering (p. 704).

Ten percent of those interviewed were categorized as embracing "prophetic instructional leadership." These leaders emphasized their work as visionaries more so than the bureaucratic aspects of instructional leadership. They saw their challenge as holding their staff accountable to a collectively defined purpose more so than increasing test scores; they pushed their teachers to think beyond the technocratic functions of schooling to the moral dimensions.

In this article, we use the term instructional leadership to mean the focus of administrators on improving classroom teaching - to affect change in the primary work of teachers - where the rubber meets the road. We further articulate this definition to include the curricular and pedagogical work that influences the "academic, civic and social-emotional" (Tredway et al., 2012 , p. 31) development of youth in and outside the classroom space.

\section{Novice Leadership}

The literature on novice leaders focuses primarily on the challenges of new leaders in acclimating to a new school. New leaders (and their ideas) are often resisted by school level actors in their new school who are entrenched in a static culture and context defined 
by prior leaders. This literature highlights the difficulties novice leaders face in learning the existing culture of the school (set by prior principals) and attempting to implement their own ideas without alienating members of the community (Langston, McClain, Stewart \& Walseth, 1998; ; Leithwood, et al., 2004; Weindling \& Dimmock, 2006).

Novice leaders are often also lost as they adjust to their new identity as a leader; the shift from a teacher identity to a leader identity leave many with an unchartered road map to follow (Crow \& Glascock, 1995). This new identity as a leader is informed by their prior experiences as teachers, their leadership preparation program and their observations of other leaders. Yet the school culture is an amalgamation of initiatives by former leaders who each brought their own understandings of what leadership should look like and novice leaders are often pressured to fit this model.

For example, in a case study of a novice assistant principal, Mariah Peete, at a racially diverse, workingclass middle school, Karpinski (2008) confirmed the challenges that novice school leaders experience in their efforts at instructional leadership as noted above. In particular, the leader under study found herself in conflict with the teachers and other school leaders as she attempted to implement new ideas that brushed up against the policies and procedures of prior assistant principals.

As these former classroom teachers move into leadership, their senses of selves, who they are and their relationships to the institution of schooling must also necessarily shift. Thus, in their first years of leadership, their identities shift from teachers who directly affect the learning of students to that of instructional leaders who indirectly affect the classroom learning of students. This shift is not a smooth, but rather an uneasy transition.

In role theory, the transition from the role of teacher to the role of a leader has been viewed as discontinuous (Loder \& Spillane, 2005). Novice leaders are often attached to their role as teacher, to the responsibilities they had as teachers and how they viewed that work. They are unable to commit, then, to the new responsibilities of being a leader. They sometimes experience "inter-role conflict" which arises due to the "differing sets of expectations and images associated with being a teacher and being a leader" (p. 266). Teachers might also distance themselves from the new role, "rationalizing that 'that person is really not me'" (p. 267). The literature, with little dissent, has overwhelmingly come to the conclusion that the roles of teacher and leader are discontinuous meaning that the work that defines each role is so different that a novice leader must "discard their former role as teachers... in order to effectively enact their new role as administrators" (p. 268).

Though their sample was comprised of all female administrators, many of the findings of Loder and Spillane (2005) likely hold for school leaders of both genders. In particular, they found that this transition from teacher to administrator was bumpy. As teachers, their world was often limited to the space of their classroom; they could close their doors to issues arising beyond their walls, leaving them somewhat in the dark about macro, school-level concerns.

Brill (2008) argued that successful leaders have in mind a decision-making process when confronted with challenging situations. While specific decisions are not generalizable, decision-making processes allow leaders to comfortably move into the unknown. Novice leaders do not have these decision-making processes in mind; rather, at this early stage of their careers, they are in the process of developing these decision-making processes. Lacking these processes, novice leaders struggle as their moral narrative compels them to act, but their inexperience provides no road map for the interaction and discussion.

Another challenge that novice administrators face is a shift in their relationships with students and teachers. With students, the relationships are marked by a distancing they perceived as necessary to maintain their authority. With teachers, they experience feeling excluded from the inner circle. Thus, they lose the sense of collegiality and, in some cases, friendships. Barth (1990) noted this in an earlier study:

Then something happens. In only a few months principals are transformed - not by choice, design, or wish - from teacher advocates to teacher adversaries. Something within the peculiar, cruel culture of schools and school systems converts good intentions into bad 
relationships and changes colleagues into superordinates and subordinates. Something in the alchemy of schools contorts friends who would help teachers into administrators who require more and tolerate less. The teacher who becomes principal emerges from the chrysalis a different species - all too often part of teachers' problems rather than their solutions. (Barth, 1990, p. 21)

Brill (2008) examined the ways that new leaders think of their multiple and overlapping roles as school leaders. He identified in his research four roles that novice leaders believe that they play in schools "enforcer, system challenger, equity promoter and instructional leader" (p.7). He found that while new leaders yearn to focus on work directly related to teaching and learning (instructional leadership and equity promoter), their work is often limited to responding to emergencies, enforcing school rules and challenging systems in place. They perceive that only a small percentage of their time is focused on their work as instructional leaders supporting teachers.

\section{Racial and Social Justice Leadership}

Drawing on Cornel West's notion of "prophetic spirituality,",Dantley (2003) called on educational leaders to redefine their work as more than single-mindedly focused on raising test scores through a technocratic and bureaucratic approach. He critiqued past views of leadership that have relied heavily on Taylorism, organizational theory and managerial approaches. Instead, Dantley offers a vision of a purpose-driven leader who works against an oppressive schooling institution that physically and symbolically violates historically marginalized populations. This is a political leadership, an activist leadership, one that criticizes, dreams, fights and embraces. Dantley described the purpose-driven leader as:

...[one who] demythologizes the educational process and critiques with critical insight the structures and forms that have traditionally ritualized what goes on in schools. The purpose of schools, especially for urban youth, is deconstructed by the purpose-driven leader who has the spiritual wherewithal to critically contextualize the conditions that define the lives of many of our youth from America's urban core.... (p. 281)

In his study of seven school leaders who identify as social justice leaders, Theoharis (2007) set out to learn about leaders who make this commitment to social justice and examined what brought them into this type of work. He found that there are three characteristics common to the social justice leaders. First, these leaders feel secure in their belief that they are right to advocate for social justice, but insecure and humble in how they go about pursuing this goal; they "lead with intense visionary passion" and they remain deeply committed to the pursuit of this vision in the face of challenges to this vision and resistance (pp. 12-18).

Synthesizing the discussions on social justice leadership work, Furman (2012) summarized, "a common understanding among many leadership scholars is that social justice focuses on the experiences of marginalized groups and inequities in educational opportunities and outcomes" (p. 4). Reviewing the literature she deduced the following about social justice leadership: "[L]eadership for social justice is action oriented and transformative, committed and persistent, inclusive and democratic, relational and caring, reflective, and oriented toward a socially just pedagogy" (Furman, 2012, p. 195). Leaders who use a social justice lens for their work are critical of the schooling institution and conscious of the "education debt" (Ladson-Billings, 2006) owed to historically oppressed and marginalized communities. This consciousness compels them to act collectively with the community to envision and enact change and, most importantly, to study and reflect on their change efforts to remain committed to action that brings about meaningful social change.

The literature Furman reviews also suggests that social justice leaders face formidable obstacles to their work in the form of teachers resistant to change, deficit theoretical lens used by families, staff and teachers, and the onslaught of neoconservatism such as the reliance on oppressive accountability measures. Theoharis (2007), in his study of seven social justice leaders, also found that they met resistance from the school, the local 
community, and at the district level. This resistance, coming seemingly from all directions, caused "physical, emotional and mental" fatigue and undermined their enthusiasm for their work (Theoharis, 2007, p. 242). Yet, they persevered using strategies such as balancing their work load with time set aside for family and turning to like-minded colleagues for support.

Others (e.g., Shields, 2010) have instead used the term "transformative leadership" to describe this critical and activist stance of social justice leaders. Transformative leadership, Shields defined as:

A form of leadership grounded in an activist agenda, one that combines a rights-based theory that every individual is entitled to be treated with dignity, respect, and absolute regard with a social justice theory of ethics that takes these rights to a societal level. It emphasizes the socially constructed nature of society.... Transformative leadership, therefore, recognizes the need to begin with critical reflection and analysis and to move through enlightened understanding to action - action to redress wrongs and to ensure that all members of the organization are provided with as level a playing field as possible - not only with respect to access but also with regard to academic, social, and civic outcomes. (Shields, 2010, pp. 571-572)

McKenzie et al. (2008) contended that there are three themes that arise in social justice leadership. First, school leaders recognize that test scores do matter and they work toward increasing those scores. Second, they "prepare students to live as critical citizens in society" (McKenzie et al., 2008, p. 116). It is not enough for all students to do well academically; they need to be prepared to engage actively in the political and social spheres. Third, social justice leaders work toward dismantling spaces of privilege, inequity and power at the school.

Rigby (2012) identified three"logics of instructional leadership" in the educational environment that influence how novice leaders in her study make sense of their own roles as instructional leaders: the prevailing logic which reifies prevalent conceptions of leadership as both managerial and instructional; the entrepreneurial logic which encourages a view of instructional leadership as the implementation of creative ideas (borrowing from the "private sector") to address issues of academic inequity; and the social justice logic which she described as "focused on the experiences and inequitable outcomes of marginalized groups, this logic challenges the current 'neutral' systems that engender the reproduction of inequality in our society. It puts forth a set of instructional leadership practices for raising the academic achievement of all students, preparing students as critical citizens, and ensuring heterogeneous, inclusive classrooms" (pp. 35-36). A social justice logic centers the education of historically oppressed populations, holding teachers accountable for using culturally responsive pedagogies and curricula to ensure the academic success of their student population. Such work often involves changing teacher practice (with the goal of also changing their deficit thinking and beliefs).

Cambron-McCabe and McCarthy (2005) defined social justice leadership as leadership concerned with "institutional and societal inequities affecting race, gender, sexual orientation, and disability but also as the assumption of an activist role for school and social change" (p. 202). Thus, such leadership is about vision, ideology, and beliefs as well as about action and social change.

Reviewing the literature on social justice leadership, they suggest practices relevant to the work of social justice leaders. Among these suggestions is, for example, the habit of studying and reflecting critically on leadership actions taken- using liberatory research methods to understand whether and/or how their school is becoming a more socially just space.

\section{Methodology and Data}

\section{Background Context}

The research context is the UC Berkeley, Leadership Support Program (LSP) - a three-year induction program in the San Francisco Bay Area that supports novice leaders in urban school districts. All participants in this research are graduates from the Principal Leadership Institute (PLI), a principal preparation program that focuses on racial and social justice, and equity. LSP is designed to assist new administrators 
in their professional growth and development, allow opportunities for them to engage in peer learning, and develop a professional network. Central to this work is that the LSP provide the support necessary for leaders to remain focused on their social and racial justice goals. Upon completion of LSP, leaders become eligible for the Professional Administrative Services (Tier II) California credential.

The participants selected for this research consisted of seven assistant principals and three principals in their first two years of administration . Four are women, six men. There are five African American, one Latina and four white leaders. At the time of the research, only one leader worked at the secondary level. All school leaders who entered the second year of the program during the 2006-2007 academic year (and remained through the third year of the program in 2007-2008) were included in the study. In the table below, we provide a brief overview of the leaders.

Table 1

Brief Overview of Study Participants

\begin{tabular}{llllll}
\multicolumn{1}{r}{ Teacher } & \multicolumn{1}{c}{ Race } & Gender & $\begin{array}{l}\text { Number of Years } \\
\text { Taught }\end{array}$ & $\begin{array}{l}\text { Position During } \\
\text { Research }\end{array}$ & School Level \\
\hline Ernest & African American & Male & 12 & Assistant Principal & Middle \\
\hline Joseph & White & Male & 8 & Principal & Elementary \\
Mary & White & Female & 25 & Assistant Principal & Elementary \& \\
Michelle & African American & Female & 5 & Assistant Principal & High \\
\hline Monique & Latina & Female & 7 & Principal & Elementary \\
\hline Natasha & White & Female & 7 & Assistant Principal Middle
\end{tabular}

As part of the second-year LSP program, these novice social justice leaders attended monthly seminars with other novice administrators. One defining aspect of the second and third years of the program is storytelling. The goal of storytelling as professional development for school leaders is for them to reflect on their practice using a narrative inquiry process. Storytelling, in this context, is more than venting; it is, as Dewey (1938) imagined, a moving force for developing conceptions about practice. Reflection and analysis often push new administrators to restructure their strategies of action and ways of framing problems (Osterman \& Kottkamp, 1993).

The purpose of storytelling is to encourage reflection and the further development of effective social justice leadership practice. Narrative plays a critical role in making meaning of experiences, constructing identity and shaping how perceptions of reality (Schon, 1991; Schon, 1987). We use story, in particular, to act as a catalyst for reflection and action.
The storytelling component helps leaders make sense of their practices and apply learned lessons to their leadership work. Further, storytelling promotes the leader's capacity to support teacher development and growth, focus on instructional practices throughout the school, and engage in difficult conversations with teachers. Finally, these stories put on display for social justice leaders (and their peers), their hard work within the organizational and political context of taking on the role of school leadership. It provides a context for leaders to "remove their capes and reveal the more authentic hand-wringing that takes place beneath the costume of the professional" (Brill, 2008, p. 2). The stories allow the leaders to validate the difficulty and complexity of this work and to return to their sites to continue working toward the improvement of student achievement. 
Methods

We collected all of the stories from the LSP participants who participated in the second and third year of the program from 2006-2008. Logistically, the second and third years of the program are when participants are regularly engaged in storytelling; following the same cohort from 2006-2008 facilitated the data collection process. For the purposes of this research presented here, then, we collected stories from the same participants over a two-year period, collecting seven stories for each participant. In total, we looked at 75 stories of ten novice social justice school leaders in their second and third years of administration in urban Bay Area schools.

At each LSP meeting, the leaders formed trios and were given a prompt that asked them to recall a moment, interaction or instance that they experienced as tense or that elicited some emotional response from them in their capacity as a leader. Stories about tense moments or that are tied to a deep emotional response pushed the reflection and reconceptualization necessary for changed leadership practice. Each story was timed, with the storyteller having ten minutes to frame the story. The two listeners, at the end of the timed session, asked reflective questions, such as "Why did you choose to tell this particular story," to help the storyteller think (and rethink) her/his actions.

The stories were transcribed and the leaders were asked to analyze their own stories with their trio. The goal was to help the storyteller think deeper about her/ his actions, leadership identity, and role in moving the school forward. The trios analyzed the stories with an attention to of race, socioeconomic status and equity as the focus of the PLI and the subsequent work in LSP is on racial and social justice. Thus, the leaders always used an equity lens to view the stories.

We analyzed these stories to better understand how novice social justice leaders think about and play the role of instructional leadership - particularly with regard to how they work with resistant teachers. Drawing from a different set of stories from the same larger dataset that we accessed, Brill (2008) had found that novice social justice leaders felt instructional leadership was critical to the social change work they needed to do in schools. Yet, they were called away from this work time and again by small fires that erupted constantly in their first years. We were interested in looking at what passed for instructional leadership for these novice social justice leaders when they were pulled in so many directions. And, in specific, we wanted to understand more about their strategies for working with underperforming teachers who resisted their intervention.

Our role as researchers analyzing their stories was a complex one. As facilitators in LSP, we were privy to the site contexts of each teller's story. As well, we had, in different capacities, worked with the tellers while they were in different stages of their preparation (either as students in the PLI or in earlier stages of their LSP experience). Thus, we had access not only to their stories and their reflections on those stories, but also to the informal data that filters through when you work closely with participants in a professional capacity. We occasionally knew how others perceived them as leaders, other perspectives on the stories told and the challenges and successes they had as leaders that did not make it into their stories. When relevant, we called on this other knowledge to help us understand the data. However, we mostly stayed with the stories as told, not interpreting them through other lenses for two reasons. First, we learned as much from the content of the "truth" of the story as we did from the "truth" as the storyteller chose to present it. How a leader framed events was as telling as the events s/he wanted to describe. Second, this research was not concerned as much with what happened as with what the novice leader had learned from what happened. The leader's perception of her/his own learning was tantamount.

We listened for the tensions that arose in their interactions with teachers as leaders attempting to support quality classroom instruction, while maintaining their roles as student advocates. These interactions included informal and formal conversations with teachers about relationships with students, pedagogy, curriculum and classroom management. These interactions have in common the effort on the part of the novice social justice leader to support teacher growth and development while holding teachers accountable for student learning.

In analyzing the data, we first pulled data that was relevant to the work that leaders do with teachers. We then searched for themes to help us understand more about the tensions that came up for them as 
they were challenged by their work as instructional leaders. We then sent off our preliminary thoughts to the participants to get their view on our findings, thus member-checking the data.

\section{Findings}

The stories of these novice social justice leaders revealed that they relied heavily on technocratic responses to address the problem of underperforming teachers. Oftentimes framing their interactions with teachers as coaching, supporting or evaluating, the school leaders in our study tended to focus on building structure and shoring up the procedural knowledge of teachers rather than focusing on content and conceptual knowledge. As well, much of the interaction between the leaders and struggling teachers was centered on documenting teacher actions (or inactions). Further, novice leaders avoided building stronger relationships with teachers, often taking steps that harmed the existing relationship. These responses of novice social justice leaders we term hyper-bureaucratized responses because they focused on clarifying procedures and increasing documentation, while ignoring the importance of building relationships with their staff. Ironically, the very critiques that they frequently had of teachers - that they do not spend time building relationships with their students - applied to the school leaders as well; they did not spend time building relationships with teachers. We selected three brief stories to illustrate each of the three aspects of hyperbureaucratized response that we found evidence of in all ten leaders' stories.

\section{Shoring Up Procedural Knowledge}

Richard, an Assistant Principal at a middle school discussed his initial hyper-bureaucratized response to teachers who referred students (particularly students of color) frequently.

Students are being kicked out of class for the most absurd reasons, where I feel the teacher has the capability and skills to handle in the classroom. There is no intervention in the classroom going on. The first thing, when something happens, they want to kick them out of class....
For example, there was a teacher who sent a student out for saying he told her that he couldn't understand her. And she kicked him out for that. And I had to send that student back to let that teacher know, "Okay, here are the proper protocols as far as sending out a student to a referral. That is not a referable offense. That is not a suspendable offense.

So I sent that student back to class and I pulled that teacher aside and I said, "This is how you fill out a referral." And she has not done it since, since I've talked to her. Because I have had to write two letters of direction to teachers and two letters of reprimand to teachers. Because when I am writing those letters I am thinking about the well being of students as well as trying to support the teacher.

After reflecting on his actions in storytelling at LSP, Richard realized that he needed a more systematic approach that built conceptual knowledge rather than simply procedural knowledge. The teacher had learned how to fill out a referral, but she had not learned how to improve her relationship with students to decrease her need to refer students. Increasing her procedural knowledge had solved the immediate problem of teachers not knowing how to fill out a referral form and, possibly, when to refer a student. But the school leader had not addressed what he later identified as underlying issues with the teacher's deficit beliefs about her students.

...[M]y concern is that I really need to have professional development for teachers to learn how to talk to students.... So what I plan to do is not only have the character education and cultural awareness program for the students, but teachers will be involved so they can observe, "Okay, how do speak to the students when they have an issue?" So the issue I have in my story, the issue I have with what I am trying to do with teachers, I really need to take a few steps back and start with educating the teachers on how to implement not only culturally relevant practices in the classroom, but how to treat a student with 
respect.

\section{Increasing Documentation}

Michelle, an Assistant Principal at a high school, discussed her efforts to support and evaluate teachers. As her story shows, she relied on evaluation (even to the extreme of firing the teacher) alone to push the development of teachers. This evaluation process included increasing the documentation of the teacher's actions in the classroom to create evidence for dismissing the teacher.

This year I was in [a struggling teacher's] classroom a lot and gave her some very concrete things that should be improved. And no, [it] hasn't improved them and yes, I did fire her. And I know in my heart that I did the right thing. My evaluations are thorough. So now I've ruined a relationship I've had with a teacher. She doesn't like me anymore. What is this firing going to really mean? Is it going to influence her teaching? Are we going to have a better teacher at the end of the year? I hope so. But I hope it isn't just a mechanism where I destroyed a relationship with a teacher and leave her feeling unsupported...

We see in this story that the leader, Michelle, believed that the evaluation and firing might influence the teacher's practices where prior suggestions for improved practice had failed. In another story that Michelle told, we see more evidence that she again relied on documentation and evaluation in place of other strategies for providing instructional leadership.

I also had to make a hard decision about athletics because we had coaches who are just not doing their job. And they're teachers at our school and they're mediocre teachers at best. I don't have a problem telling them what I expect to see. I expect to see teachers teaching and not sitting behind their laptop and I make myself pretty clear. I expect to see science class doing experiments, not crocheting or watching movies. I don't expect to walk into a classroom and it looks like a hangout. I will clear it out and write you up. I tell the teacher, "I'm going to write you up; you know that, right?" And they're like, "Ohhh, don't do that..." I write them up saying they need to improve their practices.

Again, she was limited in her repertoire for supporting teachers to documenting and evaluating. She stayed true to her goal of assuring all students had competent and motivated teachers; yet, she did not work to improve the teachers' instruction. Instead, she attempted to "evaluate them out" of the classroom.

Ernest, an AP at a middle school, also showed evidence of this habit of heavy documentation in place of other options for instructional leadership.

Ernest: And one teacher [...] told us to find coverage for his class. This was on Friday. He didn't show up that Monday or Tuesday. He happened to be an 8th grade teacher. I had observed him and I had a pre-observation conference with him. I did the observation and I had the post-observation reflections and questions that he answered. I told him I was going to write it up and had him sign the evaluation. We had done this twice in the school year before. It was always no problem...

However, in this instance, it became a problem. Ernest details a story in which the teacher gets the union involved as he begins to feel that his job is in jeopardy.

Listener: Using that as the bigger picture, where does this have you thinking in terms of crossing "I's" and dotting " $T$ ' $s$ " in terms of evaluations and formal processes and timelines?

Ernest: I still think it's really important especially in a case where you think that it's going to be a teacher that you're going to have to move on in terms of remov(ing) him from the classroom.

Documenting or evaluating a teacher out of her/his 
position was a concern for novice social justice leaders who inherit, oftentimes, tenured faculty members whose teaching practices and beliefs did not match the novice leader's social justice and equity vision.

\section{Avoiding relationship building with teachers}

The prior two sections intimate that novice social justice leaders conceived of leadership (and, in particular, instructional leadership) as linear (see literature review section, Reitzug et al., 2008). Yet, we also found evidence that they understood it as relational; that is, they believed that relationships between students and teachers was paramount to meaningful learning in the classroom. They envisioned their role as mediating these relationships, particularly for those teachers who were struggling in the classroom. A common sentiment among leaders in our sample was that students would not learn from teachers who did not take the necessary time to establish relationships with their students. Reginald, a middle school Assistant Principal, best captures how important novice social justice leaders felt the teacher-students relationship to be:

I see how that interaction between teacherchild, adult-child, administrator-child, within the school setting is just as powerful as all (the) other parts. Making sure that that is on the forefront of the conversation (with teachers); not on the back.

Ironically, though, leaders often did not view their own relationships with teachers as important. We found that novice social justice leaders did not work to build trusting relationships with their teachers, even though they encouraged their teachers to build trusting relationships with students. Rather, they struggled to establish respectful relationships with their teaching staff and often were undermined by their own inability to politically engage relationships between themselves and their teachers.

Tim, a Principal at an elementary school, told a story about his struggle to have a difficult conversation with a teacher who resisted collaborating with her peers and using commonly agreed upon practices. He appreciated much of what she offered to the school; however, her classroom practices did not meet the standard set by her grade level team (kindergarten). Below is Tim's framing of the teacher:

She doesn't plan. She leaves at 3. Gets here at 7:30 late sometimes. [She] is a great musician. She's a professional musician, so she sings the first half hour of every day. I've known this for years, but couldn't do anything about it because she told the principal that she didn't want me in her class; that I was harassing her last year. This year she can't say that. I was going in with my observation tool. I was sticking to positive stuff. It bugged me because every time I would go in, she would just wrap up [the music].... The music just seemed to be ending every time that I was there. And then the phonics piece would start. ...We talked about it in the office during her lunch break. Mistake number one. I said, "Hey. Do you have a second," and brought her into the office. That is my biggest error. It ended up getting heated on her part, [She said],"You don't want me to teach music in the school. You don't value music." I said, "This is not about music. I'm bringing more music into the school. I value the arts and music. I'm not just telling you to teach language arts all day. However, you came up with an agreement [with your grade level team]. I didn't make that agreement. You said that you were all teaching phonics starting at 8 o'clock. I come into your room and I'm not seeing that."

As the conversation escalates, the teacher proved resistant to any changes to her practice. Tim remained adamant about following the rules and procedures set by the team and further alienated the teacher.

I get a note in my box that day. The note says, "I'm taking my guitar home. It's not your fault, Tim. I know that you don't feel this way, but I guess music is just not welcome in the schools anymore." She plays the guitar and we sing our school song on Mondays. She says, "I guess you can get a $C D$ version of it so you can 
sing with the kids on Mondays." The note was

huffy and pouty. She said, "Maybe I should go

teach at School of the Arts."

After many years of trying to get the teacher to stop singing songs with her students for thirty minutes each day, Tim finally "wins" at the expense of the relationship with the teacher.

\section{Conclusion: Deepening their Commitment to Social Justice Work}

In part because of their training and in larger part because we worked with a group of leaders who self-selected into a program that is driven by a strong moral narrative, we found that our novice social justice leaders were guided heavily in their notions of instructional leadership by their beliefs that instruction in the classroom is tied heavily to social justice work. The sample of leaders in this study was, at the time, comprised of participants in LSP. They were all graduates of the PLI. As discussed earlier, the foundations of both PLI and, its sister program, LSP, are grounded in notions of equity and social justice. That is, our novice leaders pursued social justice work aimed at ameliorating racial and socio-economic injustices in the educational system, while not losing sight of other oppressions based on gender, language, sexuality and (dis)ability (to name a few) that historically manifest in inequitable educational opportunity.

We found that our leaders evidence in their stories "common leadership traits" (Theoharis, 2008) of social justice leaders. In particular, our participants exhibit two traits of social justice leaders: a complicated mix of arrogance and humility" and they "lead with intense visionary passion" (Theoharis, 2008, p. 12). In their stories, our leaders positioned themselves as the heroes in the struggle to achieve social justice ends at their schools. That is, they positioned themselves often against the backdrop of their teaching staff as righteously holding onto both the social justice mission of their school and the means to achieve this end. Yet, often in the same breath, they questioned whether their efforts were enough; they doubted and fretted about whether their work would have the intended outcome against such seemingly insurmountable odds. As well, they expressed humility in realizing that some of the decisions they made on behalf on their students adversely affected the lives of their teachers, particularly when they took steps to evaluate a teacher out of her/his job.

In the following story, Ernest discussed the challenge of evaluating a teacher out. He understood the repercussions of evaluating a teacher out - as he stated so poignantly, "This is a person's livelihood that I'm dealing with." In fact, he noted, "I really got physically ill almost just at the process."

In this particular story, Ernest discusses how he spent a great deal of time working with a teacher - both attempting to improve practices and documenting the teacher's lack of growth. In the end, Ernest decides to evaluate the teacher out. This act, as stressful as it is, serves to deepen his commitment to his social justice vision and work at the school.

Ernest: I really feel for this person, but I think he can find another job. I don't think he has quite the number of years that he would like to have in order to retire comfortably, but he does. On the other hand I feel that our students needed this to happen and they deserve this. It's been a significant experience for me because it's the first in many battles that I will have to fight for students' education. End of story.

Listener: In your quest to make sure that you knew you were doing the right thing, what kind of questions ran through your head as you were giving the teacher unsatisfactory? Ernest: Mainly it was the one question that really stood out and became sort of a monster for me. That was, "Would I want my child to be in this classroom? Would l, as a parent, allow my child to be in this classroom?" And the answer was always, unequivocally, "No." I would not stand for my child to be in a classroom where this individual was teaching...

Note, following this statement, the listener pushed Ernest to identify action steps that he took to work with the teacher. In his response, Ernest discussed how he tried to change the teacher's practices in the classroom. Ultimately, though, the teacher's deficit views of the students and families kept the teacher from investing 
in these changed practices. Instead, he continued to blame the students.

McKenzie and Scheurich (2004), in their seminal work on "equity traps," argued that equity often gets trapped - that is, leaders have a difficult time moving teacher practice and belief forward in ways that create more opportunities for students because teachers trap equity in a variety of excuses. For example, one trap is the deficit model trap. Teachers excuse inequitable outcomes in their classrooms on the students themselves - blaming the students, their assumed low intelligence, a culture of poverty and/or their families for the inequity in their classrooms. Ernest identified this trap and, in removing the teacher from the classroom, reasserted his own belief in the potential of his students.

Listener: When you said, "Would you want your child to be in that class?" that summed it all up. We want quality education for ALL students so that was a good way of putting it. Of course the person didn't take it easy, but they did take it. You had already offered ways in which they could improve to make the next evaluation be a better one and what happened?

Ernest: ...I did give him recommendations and different strategies to try. What I usually got in response during the meetings was defensive answers about the type of students who were in the classroom. Some of them were "special ed." Some of them had emotional needs according to him. Some of them had been abused so they were fearful of learning and they had very low skills. Many of them were from single parent homes and parents are not supporting him. Like he was in denial about it. It never registered that there was something he could do.

Our leaders communicate in these stories a deeply engrained social justice passion that kept them buoyed during these intensely stressful interactions about which they told their stories. They were limited in their instructional leadership repertoire to shoring up procedural knowledge and increased documentation. They even undermined their relationships with teachers, creating an "us vs. them" dynamic noted by Barth (1990). Yet, they remained committed to ensuring that every child would have an empowering classroom experience even if this meant evaluating a teacher out. This visionary passion kept them afloat through tides of underperforming and resistant teachers, tense staff meetings and district mandates at odds with their implementation ideas. 


\section{REFERENCES}

Barth, R. (1990). Improving schools from within. San Francisco: Jossey-Bass.

Bell, D. (1980). Brown v. Board of Education and the interestconvergence dilemma. Harvard Law Review, 93(3), 518533.

Brill, F. S. (2008). Leading and learning: Effective school leadership through reflective storytelling and inquiry. Portland: Stenhouse Publishers.

Bryk, A.S., Sebring, P.B., Allensworth, E., Luppescu, S., \& Easton, J. (2010). Organizing schools for improvement: Lessons from Chicago. Chicago, IL: The University of Chicago Press.

Cambron-McCabe, N. and McCarthy, M.M. (2005). Educating school leaders for social justice. Educational Policy, 19(1), 201-222.

Crow, G.M., and Glascock, C. (1995). Socialization to a new conception of the principalship. Journal of Educational Administration, 33(1), 22-43.

Cuban, L. (2010). Principal turnover: "Burn and churn" strategies and student academic achievement. Retrieved June 2012, from http://larrycuban.wordpress. com/2010/04/24/principal-turnover-burn-and-churnstrategies-and-student-academic-achievement/, June 2012.

Dantley, M. (2003). Purpose-driven leadership: The spiritual imperative to guiding schools beyond high-stakes testing and minimum proficiency. Education and

Urban Society, 35(3), 273-291.

Delgado, R. (1989). Storytelling for oppositionists and others: A plea for narrative. Michigan Law Review, 87, 2411-2441.

Dewey, J. (1938). Experience and education. New York: Simon and Schuster.

Dixson, A. and Rousseau, C. (2006). Introduction. In A. Dixson \& C. Rousseau (Eds.). (2006). Critical race theory in education: All God's children got a song. New York, NY: Routledge.

Furman, G. (2012). Social justice leadership as praxis: Developing capacities through preparation programs. Educational Administration Quarterly, 48(2), 191-229.

Karpinski, C.F. (2008). "This is MY school, NOT YOURS": A novice assistant principal's attempt to lead. Journal of Cases in Educational Leadership, 11(1), 87-96.
Ladson-Billings, G. (2006). 2006 presidential address: From the achievement gap to the education debt: Understanding achievement in U.S. schools. Educational Researcher, 35(7), 3-12.

Ladson-Billings, G. and Tate, W.F. (1995). Toward a critical race theory of education. Teachers College Record, 97(1), 47-68.

Langston, R., McClain, G., Stewart, B., and Walseth, J. (1998). An exploration of strategies which elementary principals new to their schools use to learn about their school culture. Washington, DC: Office of Educational Research and Improvement.

Lawrence, C. (1995). The word and the river: Pedagogy as scholarship as struggle. In K. Crenshaw, N. Gotanda, G. Peller, \& K. Thomas (Eds.), Critical race theory: The key writings that formed the movement. New York, NY: New Press.

Leithwood, K., Louis, K. S., Anderson, S., \& Wahlstrom, K. (2004). How leadership influences student learning: Report to the Wallace Foundation. Minneapolis, MN: University of Minnesota, Center for Applied Research and Educational Improvement.

Loder, T. L. and Spillane, J. (2005). Is a principal still a teacher?: U.S. women administrators' accounts of role conflict and role discontinuity. School Leadership

and Management, 25(3), pp. 263-279.

Louis, K. S., Leithwood, K., Wahlstrom, K. L., and Anderson, S. E. (2010). Investigating the links to improved student learning: Final report of research findings. Learning from leadership project. St. Paul, MN: University of Minnesota, Center for Applied Research and Educational Improvement.

McKenzie, K.B. \& Scheurich, J.J. (2004). Equity traps: A useful construct for preparing principals to lead schools that are successful with racially diverse students. Education Administration Quarterly, 40, 601-632.

McKenzie, K.B., Christman, D.E., Hernandez, F., Fierro, E., Capper, C.A., Dantley, M., Gonzàlez, M.L., CambronMcCabe, N, and Scheurich, J.J. (2008). From the field: A proposal for educating leaders for social justice. Educational Administration Quarterly, 44(1), 111-138.

Oakes, J. (1985/2005). Keeping track: How schools structure inequality. New Haven, CT: Yale University Press.

Osterman, K. \& Kottkamp, R. (1993). Reflective practice for educators: Professional development to improve student learning. Thousand Oaks, CA: Corwin Press.

Picower, B. (2009). The unexamined Whiteness of teaching: How White teachers maintain and enact dominant racial ideologies. Race, Ethnicity and Education, 12(2), 197-215. 
Reeves, D. (2004). Assessing educational leaders: Evaluating performance for improved individual and organizational results. Thousand Oaks, CA: Corwin Press.

Reitzug, U.C., West, D.L., and Angel, R. (2008). Conceptualizing instructional leadership: The voices of principals. Education and Urban Society, 40(6), 694-714.

Rigby, J.G. (2012). First-Year principals' engagement with instructional leadership: The presence, pathway, and power of institutional logics. Unpublished doctoral dissertation. University of California, Berkeley.

Schon, D.A. (1991). The reflective turn: Case studies in and on educational practice. New York, NY: Teachers College Press.

Schon, D.A. (1987). Educating the reflective practitioner: Toward a new design for teaching and learning in the professions. San Francisco, CA: Jossey-Bass.

Shields, C.M. (2010). Transformative leadership: Working for equity in diverse contexts. Educational Administration Quarterly, 46(4), 558-589.

Tatum, B.D. (1997). "Why are all the Black kids sitting together in the cafeteria?" and other conversations about race. New York, NY: Basic Books.

Theoharis, G. (2007). Social justice educational leaders and resistance: Toward a theory of social justice leadership. Educational Administration Quarterly, 43(2), 221-258.

Theoharis, G. (2008). Woven in deeply: Identity and leadership of urban social justice principals. Education and Urban Society, 41(1), 3-25.

Tredway, L., Stephens, D., Leader-Picone, L. \& Hernandez, J. (2012). Leadership Connection Rubric: Supporting Equity in the Schools We Need. Berkeley, CA: Leadership Connection.

Weindling, D., \& Dimmock, C. (2006). Sitting in the 'hot seat': New headteachers in the UK. Journal of Educational Administration, 44(4), 326-340. 
